\title{
Article
}

\section{Rare earth mineral diversity controlled by REE pattern shapes}

\author{
Michael Anenburg* (D) \\ Research School of Earth Sciences, Australian National University, Canberra, ACT 2600, Australia.
}

\section{Abstract}

The line connecting rare earth elements (REE) in chondrite-normalised plots can be represented by a smooth polynomial function using $\lambda$ shape coefficients as described by O’Neill (2016). In this study, computationally generated $\lambda$ combinations are used to construct artificial chondrite-normalised REE patterns that encompass most REE patterns likely to occur in natural materials. The dominant REE per pattern is identified, which would lead to its inclusion in a hypothetical mineral suffix, had this mineral contained essential REE. Furthermore, negative Ce and $\mathrm{Y}$ anomalies, common in natural minerals, are considered in the modelled REE patterns to investigate the effect of their exclusion on the relative abundance of the remainder REE. The dominant REE in a mineral results from distinct pattern shapes requiring specific fractionation processes, thus providing information on its genesis. Minerals dominated by heavy lanthanides are rare or non-existent, even though the present analysis shows that REE patterns dominated by $\mathrm{Gd}$, Dy, Er and $\mathrm{Yb}$ are geologically plausible. This discrepancy is caused by the inclusion of Y, which dominates heavy REE budgets, in mineral name suffixes. The focus on Y obscures heavy lanthanide mineral diversity and can lead to various fractionation processes to be overlooked. Samarium dominant minerals are known, even though deemed unlikely by the computational model, suggesting additional fractionation processes that are not well described by $\lambda$ shape coefficients. Positive Eu anomalies only need to be moderate in minerals depleted in the light REE for Eu to be the dominant REE, thus identifying candidate rocks in which the first Eu dominant mineral might be found. Here, I present an online tool, called $A L a m b d a R$ that allows interactive control of $\lambda$ shape coefficients and visualisation of resulting REE patterns.
\end{abstract}

Keywords: rare earth elements, mineral evolution, lambda shape coefficients, europium anomaly, cerium anomaly, orthogonal polynomials, lanthanides, normalisation

(Received 24 April 2020; accepted 8 September 2020; Accepted Manuscript published online: 11 September 2020; Associate Editor: Koichi Momma)

\section{Introduction}

\section{Overview of REE patterns}

The series of elements from La through to Lu are known as the lanthanides. Under typical geological conditions they occur as trivalent cations with the exception of Ce (also often tetravalent) and $\mathrm{Eu}$ (often also divalent). Their valence electron structures are similar, and cationic radii vary quadratically from the large $\mathrm{La}^{3+}$ to the small $\mathrm{Lu}^{3+}$ due to the lanthanide contraction (Raymond et al., 2010; Seitz et al., 2007). This contraction, together with its effect on mesoscale molecular interactions (Ferru et al., 2016) leads to small yet gradual and predictable changes in their chemical behaviour. Yttrium is positioned above the lanthanides in group 3 of the periodic table, and it often behaves like Dy or Ho, particularly in high-temperature igneous or metamorphic environments (Pack et al., 2007). The lanthanides and Y, excluding the unstable Pm (whose natural abundance is negligible, Kuroda, 1982), are often grouped together as the rare earth elements (REE: Balaram, 2019; Cheisson and Schelter, 2019). Subsets of the REE group that commonly occur together in various rocks and minerals are termed as the light REE (LREE), heavy REE (HREE), and less commonly, the middle REE (MREE), with the exact boundaries between the subsets varying between

\footnotetext{
*Author for correspondence: Michael Anenburg, Email: michael.anenburg@anu.edu.au Cite this article: Anenburg M. (2020) Rare earth mineral diversity controlled by REE pattern shapes. Mineralogical Magazine 84, 629-639. https://doi.org/10.1180/mgm.2020.70
}

authors. Often, the LREE group includes La to Sm, whereas the HREE group includes Eu to Lu. The MREE group, when used, typically includes Sm to Dy. The smooth variation in the chemical properties between the REE allows systematic fractionation from each other, and studies into these processes provide windows into a variety of geochemical and cosmochemical processes.

Although differences between the REE chemical properties are gradual, the variation in their natural abundances is not. They follow the Oddo-Harkins rule, which states that elements with even atomic numbers (e.g. Dy) are more abundant than their neighbouring odd-numbered elements (e.g. Tb and Ho) (Harkins, 1917; Palme et al., 2014). This complicates comparison of subtle differences between rocks or minerals because of the characteristic zig-zag shape of REE abundance plots (Taylor, 1962). The difficulty is resolved by normalisation to REE contents of a representative primitive or primordial reservoir, most commonly CI chondrites (Coryell et al., 1963). When plotted in a logarithmic scale, the normalisation results in generally smooth REE patterns in which fractionation trends become obvious, facilitating the use of REE patterns as petrogenetic tools.

A practical limitation stems from the appearance of each analysis as a line on REE plots, which convolutes studies of large analytical data sets owing to visual overload. O’Neill (2016) developed a method to represent REE patterns by the polynomial:

$$
\ln \left(\frac{[\mathrm{REE}]}{[\mathrm{REE}]_{\mathrm{CI}}}\right)=\lambda_{0}+\lambda_{1} \mathrm{f}_{1}+\lambda_{2} \mathrm{f}_{2}+\ldots,
$$




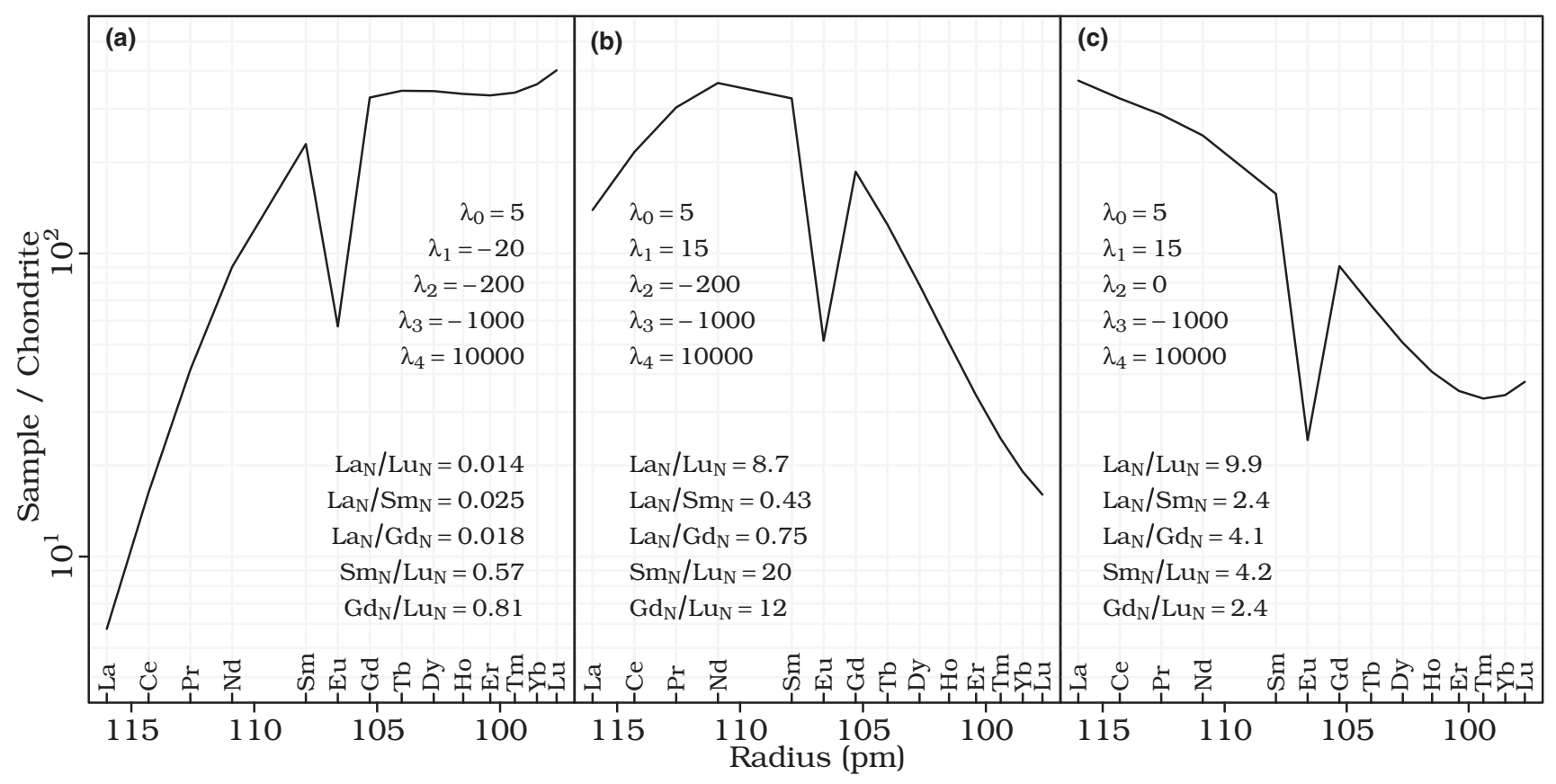

Fig. 1. Three different REE patterns generated from a set of $\lambda$ coefficients and Eu anomaly set at 0.2. Chondrite-normalised element ratios are calculated for each pattern and annotated on the figure.

where $[\mathrm{REE}]$ and $[\mathrm{REE}]_{\mathrm{CI}}$ are measured and chondritic abundance of each REE, respectively, $\lambda_{n}$ are shape coefficients, and $\mathrm{f}_{n}$ are precalculated orthogonal polynomials in $r_{\mathrm{VIII}}^{3+}$, the ionic radius of trivalent cations in eight-fold coordination from Shannon (1976) for each respective REE. The orthogonality of the polynomials ensures that the shape coefficients are independent of each other so that, for example, truncating the polynomial series at $\lambda_{n} \mathrm{f}_{n}$ does not affect the values of $\lambda_{n-1}$ etc. The process of deriving $\lambda$ shape coefficients from a REE pattern can be achieved using dedicated software such as the spreadsheet available in the Supplementary data of O'Neill (2016), or the Python package 'pyrolite' (Williams et al., 2020). Most REE patterns can be closely reproduced by three to four shape coefficients, where the physical significance of $\lambda_{0}$ is the overall abundance of the REE, $\lambda_{1}$ is the linear slope, $\lambda_{2}$ is the quadratic curvature and $\lambda_{3}$ represents the inflections at the ends of patterns (sinusoidality). Rarely, a fifth $\lambda_{4}$ term is required if any ' $W$ ' shape is present in the pattern. Representation of REE patterns by their $\lambda$ shape coefficients reduces the dimension of each analysis from a line to a point that can be plotted in $\lambda$-space. Often, $\lambda_{2}-\lambda_{1}$ plots (quadratic curvature versus slope) are the most instructive (O’Neill, 2016).

\section{Quantitative description of REE pattern shapes}

The merit of using $\lambda$ shape coefficients instead of other pattern shape indicators is now discussed. Various shape aspects of REE patterns are often described quantitatively with normalised element ratios (denoted by subscript ${ }_{\mathrm{N}}$ ). For example, $\mathrm{La}_{\mathrm{N}} / \mathrm{Lu}_{\mathrm{N}}$ is a measure of the overall slope of the pattern, whereas $\mathrm{La}_{\mathrm{N}} /$ $\mathrm{Sm}_{\mathrm{N}}$ might be a measure of the LREE enrichment of a pattern. However, these ratios fail to capture some of the complexities that often occur in patterns, such as curvature or sinusoidality. When ratios are used, the choice of elements is often arbitrary, with some workers choosing Ce over $\mathrm{La}, \mathrm{Nd}$ or Gd over Sm, and $\mathrm{Yb}$ over Lu. This inconsistency can lead to biases depending on the hypothesis in discussion, as these diagrams are plotted on logarithmic scales and small distances in the vertical scale often translate to large differences in element ratios. Finally, these ratios are not independent of each other. This problem is illustrated in Fig. 1. Garnets, for example, commonly have REE patterns with strongly depleted LREE contents which steeply rise towards the MREE, and the HREE are usually sub-horizontal. The REE pattern generated from $\lambda$ values shown in Fig. $1 a$ is an example of such a garnet-like pattern. Several normalised element ratios are calculated in order to provide information on the shape. $\mathrm{La}_{\mathrm{N}}$ over $\mathrm{Lu}_{\mathrm{N}}, \mathrm{Sm}_{\mathrm{N}}$ and $\mathrm{Gd}_{\mathrm{N}}$ are small numbers, confirming the overall strongly positive slope of the pattern. $\mathrm{Sm}_{\mathrm{N}} / \mathrm{Lu}_{\mathrm{N}}$ and $\mathrm{Gd}_{\mathrm{N}} / \mathrm{Lu}_{\mathrm{N}}$ are close to unity, reflecting the flattening of the HREE. Rare earth element patterns for garnets often exhibit their inflection point at $\mathrm{Eu}$, which would make it an ideal element to use in ratios. However, due to the redox behaviour of $\mathrm{Eu}$ it occasionally shows negative or positive anomalies, rendering it useless for this purpose. The pattern in Fig. $1 a$ is then rotated clockwise by increasing $\lambda_{1}$ from -20 to 15 , while the terms describing curvature $\left(\lambda_{2}\right.$ to $\left.\lambda_{4}\right)$ remain fixed, leading to the expected increase of $\mathrm{La}_{\mathrm{N}} /$ $\mathrm{Lu}_{\mathrm{N}}$ (Fig. 1b). However, all other ratios shown in Fig. $1 b$ also increase by more than an order of magnitude. If the purpose of ratios (i.e. those involving Sm and Gd) is to provide some information about the curvature (e.g. Davidson et al., 2013), then they clearly fail because the curvature has not been modified. Additionally, it is now difficult to infer from these ratios that the HREE line is nearly straight. The correlation between normalised elemental ratios increases the challenges for their interpretation when the variation between REE patterns includes more than just the slope. Fig. $1 c$ shows the pattern from Fig. $1 b$, but with the quadratic curvature term eliminated (i.e. $\lambda=0$ ). $\mathrm{La}_{\mathrm{N}} /$ $S m_{N}$ and $\mathrm{La}_{\mathrm{N}} / \mathrm{Gd}_{\mathrm{N}}$ increase whereas $\mathrm{Sm}_{\mathrm{N}} / \mathrm{Lu}_{\mathrm{N}}$ and $\mathrm{Gd}_{\mathrm{N}} / \mathrm{Lu}_{\mathrm{N}}$ decrease. These changes are reversed in positively sloping patterns (i.e. $\mathrm{La}_{\mathrm{N}} / \mathrm{Lu}_{\mathrm{N}}<0$ ), even though the change in quadratic curvature is identical. Consequently, these ratios become meaningless in 
many cases, for instance in analyses of rock suites containing both positively and negatively sloping REE patterns. Methods of measuring curvature by interpolation (e.g. Dy/Dy*, Davidson et al., 2013) are likewise not independent and can be compromised by other shape features in a pattern (e.g. sinusoidality). Additional applications of the $\lambda$ method are described by O'Neill (2016). As the method is new and not yet widely adopted, it may be difficult to understand intuitively and visualise how each $\lambda$ coefficient affects the shape of the REE patterns. This article is accompanied by an interactive online app (ALambdaR), briefly described in the Appendix, which allows independent experimentation with construction of REE patterns from $\lambda$ shape coefficients.

\section{Artificial REE patterns}

O'Neill (2016) originally intended for the $\lambda$ shape coefficients to be used as a tool for interpretation of natural REE patterns. However, as mentioned above, the shape coefficients are orthogonal and not correlated with each other. This means that each shape coefficient can be varied independently, allowing one shape component of a pattern (e.g. curvature) to vary while others (e.g. slope and sinusoidality) remain fixed. This property can be used to construct artificial REE patterns that cover all possible REE patterns representable by the $\lambda$ shape coefficients. These include a large proportion of all smoothly-varying REE patterns in Nature.

In this study I show how artificial REE patterns are constructed. A simple application is demonstrated, whereby the most abundant REE in a pattern is identified as a function of the $\lambda$ shape coefficients. As the most abundant REE gives its name to a rare earth mineral via the Levinson suffix, this study has implications for prediction of yet unknown mineral species and mineral evolution, and it provides an example of the datadriven abductive approach to mineralogy (Hazen, 2014). The two most common REEs, Ce and Y, can also behave anomalously under certain conditions. The effect of their removal is examined in this study.

\section{Methods}

A script using the $R$ programming language was written to generate REE patterns from combinations of $\lambda$ shape coefficients (available in the Supplementary data, with a mathematical treatment of the process available in the Appendix). A graphical user interface is provided in the accompanying online app (ALambdaR) to simplify and automate the processes and readers are encouraged to experiment with the effect of various $\lambda$ coefficient combinations.

In this study, only the overall pattern shape is of importance, and therefore $\lambda_{0}$ can be neglected as it merely shifts a pattern up or down on a chondrite-normalised plot. Only two variables can be easily conveyed in $2 \mathrm{D}$ plots. Consequently, the slope and curvature coefficients are used as the horizontal and vertical axes, and cover the ranges $\lambda_{2}=[-750,750]$ and $\lambda_{3}=[-6500$, 6500] at intervals of 4 and 40 , respectively. The other coefficients are fixed at $\lambda_{1}=\{-25,-17,-12,-9,-7,-5,-3,0,5,15\}$ and $\lambda_{4}=$ $\{-40,000,0,40,000\}$, with each combination shown by a single panel in the following plots.

A total of $10 \times 376 \times 326 \times 3=3,677,280$ unique REE patterns were generated. Yttrium is added to each pattern according to a chondritic $\mathrm{Y} / \mathrm{Ho}=25.5$. Next, the most abundant REE on an atomic basis is identified for each pattern, and the ratio between that element and $\mathrm{Eu}$ is calculated. This process is repeated while disregarding $\mathrm{Ce}$ and $\mathrm{Y}$ to account for possible negative anomalies.

\section{Results and discussion}

The range of different REE patterns generated in this study is shown in Fig. 2. Each panel represents a combination of single $\lambda_{1}$ and $\lambda_{4}$, and range of $\lambda_{2}$ and $\lambda_{3}$ values. Representative REE patterns are plotted in their respective positions in the panels. The reader is encouraged to recreate the patterns using the accompanying online app (ALambdaR) to better appreciate the $\lambda$ concept. A careful examination of how patterns vary with $\lambda_{1}$ to $\lambda_{4}$ allows one to intuitively grasp the meaning of each shape coefficient and how they interact when combined linearly. Those who have worked with REE before will soon recognise that many natural patterns (excepting $\mathrm{Ce}$ or Eu anomalies) closely resemble the patterns in Fig. 2, particularly at $\lambda=0$. Conversely, some extreme values such as those at $\lambda_{2}>500$ are probably unrealistic. Generally speaking, patterns at and around the centre are the most likely patterns that appear in Nature due to the largely systematic variation between neighbouring REE described by $\lambda_{2}$ and $\lambda_{3}$ close to zero.

The most abundant REE on an atomic basis in a pattern are depicted in Fig. 3. The pattern can be seen by recreating it in the online app, or by referring back to the same $\lambda$-coordinates in Fig. 2. The respective point on each panel is then coloured according to the most abundant REE. As similar patterns result from similar REE contents, the most abundant REE form similarly-coloured regions which encompass REE pattern families. For example, the labelled panel in Fig. $3 i$ shows four regions, each dominated by $\mathrm{La}, \mathrm{Ce}, \mathrm{Nd}$ and $\mathrm{Y}$. By comparing it with its respective panel in Fig. $2 s$, it can be seen that: (1) the rightmost La-dominated part of the panel indeed contains REE patterns with strong La enrichments; (2) the bottom-right Ce-dominated part of the panel contains REE patterns with LREE enrichment but an inflection point that lowers $\mathrm{La}$ contents relative to $\mathrm{Ce}$; (3) the bottom Nd-dominated part of the panel corresponds with patterns strongly enriched in the lighter MREE; and (4) the Y-dominated remainder consists of all other patterns.

The predominant REE in each pattern strongly depends on whether $\mathrm{Y}$ and $\mathrm{Ce}$ are present. When included in the calculation, negatively sloping patterns (i.e. $\lambda_{1}<0$ ) are dominated by $\mathrm{Y}$, with some $\mathrm{Yb}$ in the unrealistically high $-\lambda_{2}-$ low $-\lambda_{3}$ cases (Fig. 3). As the patterns flatten and then begin to slope positively (i.e. $\lambda_{1} \geq 0$ ), the dominance of $\mathrm{La}, \mathrm{Ce}$ and $\mathrm{Nd}$ expands at the expense of $\mathrm{Y}$ and $\mathrm{Yb}$.

Rare earth element patterns of most crustal rocks are either weakly positively sloping or negatively sloping (i.e. $-5 \lesssim \lambda_{2}$ $\lesssim 15$, Fig. 2), have little curvature or sinusoidality (i.e. would plot close to the centre of each panel), with negligible Ce and Y anomalies (O’Neill, 2016). The second row of Fig. $3(f-j)$ shows that these patterns are dominated by either $\mathrm{Y}$ or Ce. This is in perfect agreement with currently known REE minerals, and a consequence of their crustal abundance, with Ce being the most abundant LREE at $63 \mu \mathrm{g} \mathrm{g}^{-1}$ and $\mathrm{Y}$ being the most abundant HREE at $21 \mu^{-1} g^{-1}$ (Rudnick and Gao, 2014). There are 112 Y minerals (i.e. REE-essential minerals dominated by Y) and 137 Ce minerals, which together account for $75.7 \%$ out of all IMA-approved REE minerals (see McLeod and Shaulis, 2018 for an analysis of REE mineral occurrences). These two are followed by $\mathrm{La}(46$ minerals, or $14.0 \%), \mathrm{Nd}(27$, or $8.2 \%)$ and $\mathrm{Yb}(4$, or 

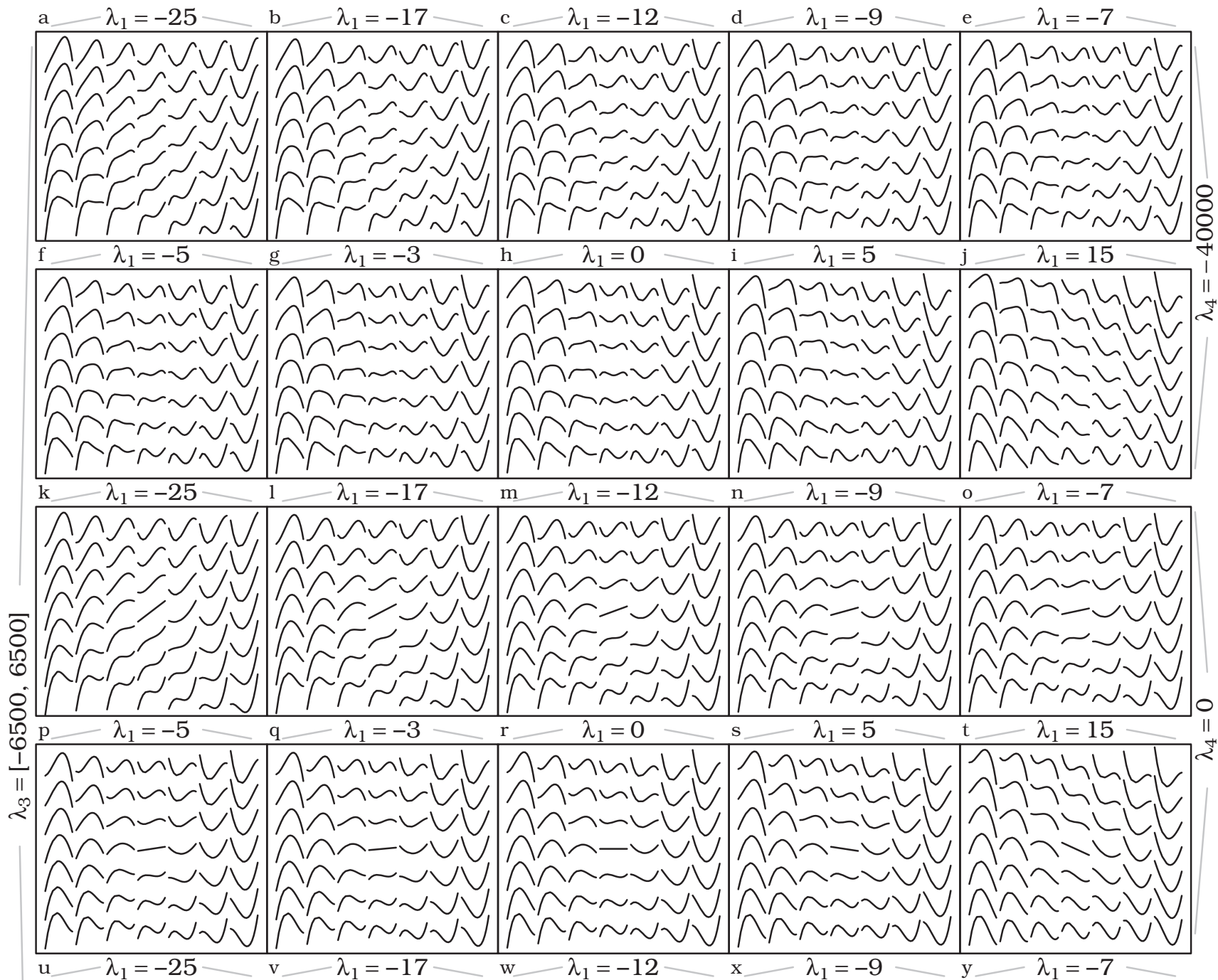

(n)

Fig. 2. A representative example of REE patterns, drawn in a qualitative but consistent scale. Each panel has discrete $\lambda_{1}$ and $\lambda_{4}$ indicated by the annotation above each panel and on the right side. Within each panel, the horizontal axis covers $\lambda_{2}=[-750,750]$, and the vertical axis covers $\lambda_{3}=[-6500,6500]$. $\lambda_{2}$ and $\lambda_{3}$ are 0 at the centre of each panel.

1.2\%). The $\sim$ factor-of-two predominance of La over $\mathrm{Nd}$ minerals is puzzling, as their crustal abundances are similar (La at $31 \mu \mathrm{g} \mathrm{g}^{-1}$ and $\mathrm{Nd}$ at $27 \mu \mathrm{g} \mathrm{g}^{-1}$ ) (Rudnick and Gao, 2014), and the La field is located at the right-hand side of each panel in Fig. 3, which was described above as less likely to occur in natural rocks. This issue can be resolved if negative $\mathrm{Ce}$ anomalies are considered. 


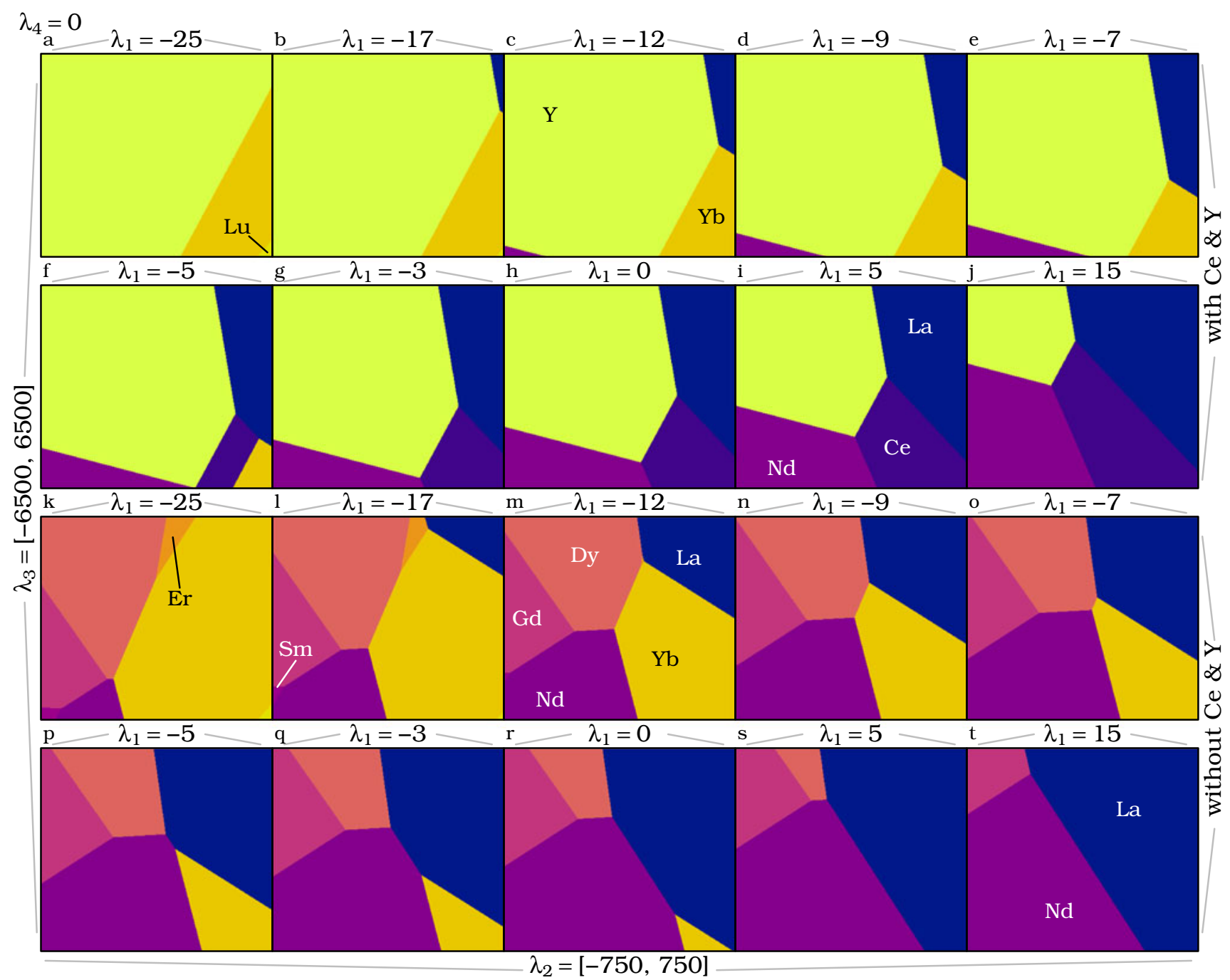

Fig. 3. A comparison between the dominant element of each pattern including Ce and $Y$ (top two rows) and excluding Ce and $Y$ (bottom two rows) with $\lambda_{4}$ fixed at 0 . Colours indicate individual elements. Not all fields are annotated, but colours are consistent. A full colour key is available in the Supplementary materials. $\lambda_{1}$ to $\lambda_{3}$ are similar to Fig. 2 .

The lower two rows in Fig. $3 k-t$ show the same calculation, but without $\mathrm{Ce}$ and $\mathrm{Y}$. The area previously occupied by $\mathrm{Ce}$ is now shared between $\mathrm{La}$ and $\mathrm{Nd}$, with the boundary between the two occurring at the centre of most panels. Rare earth element minerals tend to occur in REE-rich rocks which often include carbonatites and peralkaline rocks (Chakhmouradian and Zaitsev, 2012; Dostal, 2017; McLeod and Shaulis, 2018; Verplanck et al., 2016). These rocks often have strongly negatively sloping REE patterns, which are represented by patterns with $\lambda_{2}>0$, well within the La field of Fig. 2, explaining the large diversity of La-dominated minerals (Krivovichev and Charykova, 2017).

The Ce-Y-absent plots (bottom half of Fig. 3) also show the potential for HREE-dominant minerals. The largest HREE field in most panels is the $\mathrm{Yb}$ field and indeed there are four known $\mathrm{Yb}$ minerals. The Dy fields reach the centre of most plots, suggesting that Dy-dominated minerals are likely to occur in Nature. However, none are yet known, probably because of the high abundance of $\mathrm{Y}$ in these minerals (see discussion below). Likewise, the Gd fields are significant and reach areas near the centre of the plots, but only one Gd mineral is known at present (Deliens and Piret, 1982). Additionally, small Er and Sm fields occur in the $\lambda_{1}=-25$ and $\lambda_{1}=-17$ plots. No Er minerals are currently known. Surprisingly, even though the Sm fields occur in the lower left corners, there are two Sm minerals known. A possible reason is that these corners correspond to places where $\mathrm{Y}$ is less abundant (compare the positions of the Sm fields with the same positions in the top two rows of Fig. $3 a-j$ ), thus merely requiring a small negative $\mathrm{Y}$ anomaly for $\mathrm{Sm}$ to predominate. Alternatively, the Er and Sm fields are enlarged when $\lambda_{4}$ deviates from zero. Fig. 4 shows an enlarged Er field at $\lambda_{4}=-40,000$ and enlarged Sm field (along with Gd) at $\lambda_{4}=40,000$ that impinge on the geologically reasonable panel centres.

The REE appearing in Figs 3 and 4 correlate closely with the Oddo-Harkins rule. The plots contain mostly elements with even atomic numbers (Ce, Nd, Sm, Gd, Dy, Er and $\mathrm{Yb}$ ). The only odd-numbered elements that reach dominance are La and $\mathrm{Lu}$, which occur on opposite edges of the REE series. The primary reasons for La dominance were described above, but another reason is that both $\mathrm{La}$ and $\mathrm{Lu}$ are bounded by only one evennumbered REE ( $\mathrm{Ce}$ and $\mathrm{Yb}$, respectively) instead of two like all 


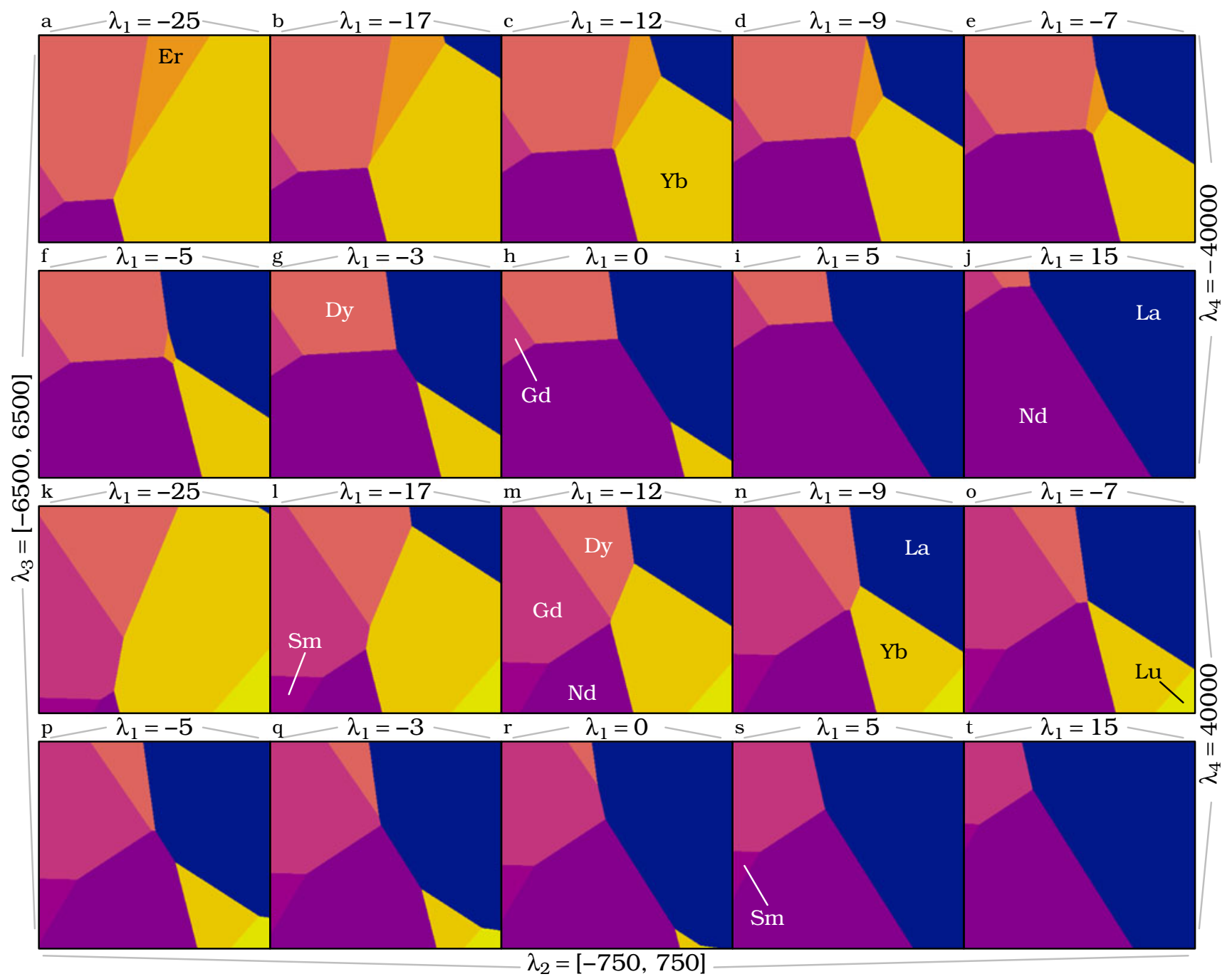

Fig. 4. A comparison between the dominant element for each pattern excluding Ce and Y. Construction of panels is similar to Fig. 3 , with the top two rows showing $\lambda_{4}=-40,000$ and the bottom two rows showing $\lambda_{4}=40,000$. Inclusion of Ce and $Y$ results in panels almost identical to the top two rows of Fig. 3 , which are not shown here.

other odd-numbered REE. Finally, Lu appears only on some plots at highly unrealistic $\lambda_{2} \gg 0$ and $\lambda_{3} \ll 0$, so it will never overtake the abundance of $\mathrm{Yb}$ for all practical purposes. The Oddo-Harkins rule is well demonstrated with Pr, which has the fourth largest crustal abundance of all lanthanides, and fifth when including Y. However, no predicted REE pattern contains Pr as the most abundant REE, even when excluding the neighbouring Ce, because $\mathrm{Nd}$ is much more abundant than Pr. It may be possible to concentrate $\mathrm{Pr}$ by fractionating it from the other REE by oxidation to $\mathrm{Pr}^{4+}$, but hitherto only trace amounts of $\mathrm{Pr}^{4+}$ have been detected in terrestrial rocks (Anenburg et al., 2020a).

\section{Europium anomalies}

The anomalous redox behaviour of Eu allows its concentration in Ca-rich minerals, most notably plagioclase and epidote (Anenburg et al., 2015; Bédard, 2006; Bieseler et al., 2018; Frei et al., 2004; Rudnick, 1992; Schoneveld and O’Neill, 2019). It is possible to calculate the stage at which Eu becomes the most abundant REE in a mineral by calculating the ratio between the most abundant REE and Eu. The result is the minimum positive $\mathrm{Eu}$ anomaly required for it to predominate. Generally, Eu anomalies are calculated using the geometric mean of the neighbouring elements by $\mathrm{Eu} / \mathrm{Eu}^{*}=\mathrm{Eu} / \sqrt{\mathrm{Sm} \times \mathrm{Gd}}$, however this can lead to errors in patterns with strong curvature at Eu (see Fig. 5). Here, $\mathrm{Eu}$ anomalies are calculated relative to the expected $\mathrm{Eu}$ from the polynomial fit.

Figure 6 shows the Eu anomaly required for it to predominate at different $\lambda$ values. As above, the removal of Ce and Y allows for smaller $\mathrm{Eu}$ anomalies to suffice. The greatest influence comes from $\lambda_{2}$, which reduces the required anomaly as it becomes more negative. This is expected as patterns with negative $\lambda_{2}$ are parabolic with maxima precisely at Eu. The required $\mathrm{Eu}$ anomalies close to the plot centres are often in the range of 5 to 10 , which is a reasonable value often seen in nature. Prolonged surface weathering often leads to concentration of $\mathrm{REE}$, and it is probable that Eu-dominated minerals will form in strongly weathered anorthosites or epidosites (e.g. Banerjee and Chakrabarti, 2018). 


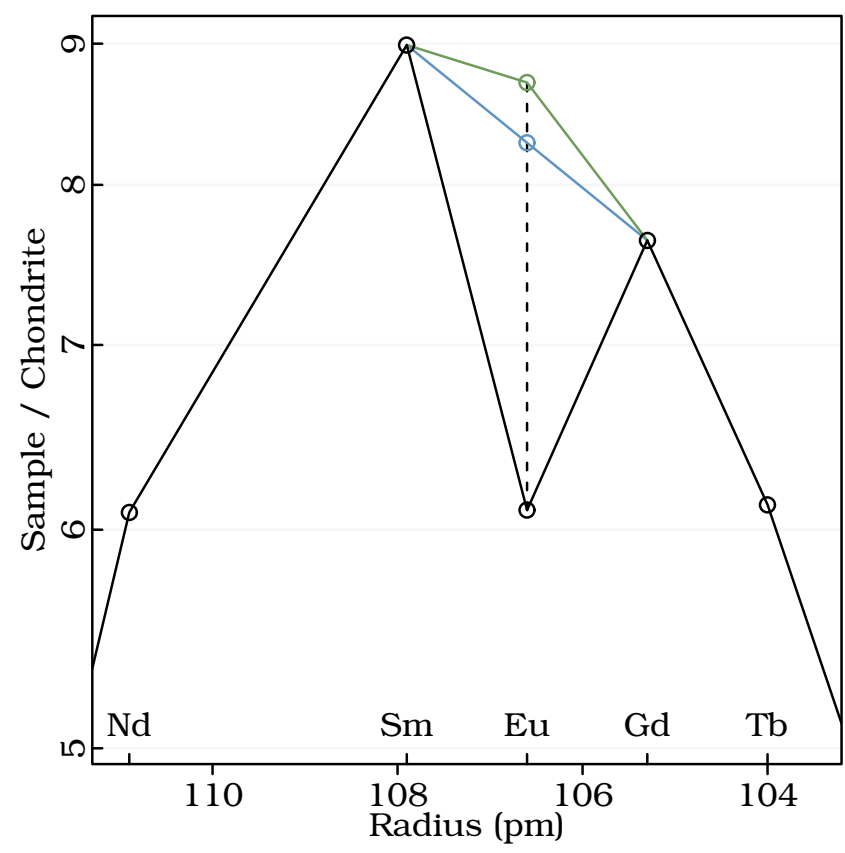

Fig. 5. $\mathrm{A} \mathrm{Nd}$-Tb portion of a pattern generated with $\lambda_{0}=1, \lambda_{1}=0, \lambda_{2}=-300$, and $\lambda_{3}=-1000$ and no Eu anomaly (green line). However, an attempt to calculate the anomaly using interpolation of the neighbouring elements (blue line) leads to $\mathrm{Eu} / \mathrm{Eu} *=\mathrm{Eu} / \sqrt{\mathrm{Sm} \times \mathrm{Gd}}=1.05$, suggesting a small positive, yet spurious, $\mathrm{Eu}$ anomaly.

\section{Comparison with natural minerals}

Rare earth element patterns and polynomial fits calculated from data available for four $\mathrm{Yb}$ minerals and two Sm minerals are given in Fig. 7. The polynomial fits to the $\mathrm{Yb}$ minerals reasonably agree with the observed patterns. Likewise, projection of their coefficients into $\lambda_{2}-\lambda_{3}$ space shows they all plot within their respective $\mathrm{Yb}$ fields (marked by similarly coloured lines). In contrast, the polynomial fits to the Sm minerals fail to reproduce the high Sm contents. Moreover, their projections plot outside of the Sm-dominant fields in $\lambda_{2}-\lambda_{3}$ space. This could result from analytical challenges as the REE are measured by wavelengthdispersive spectroscopy, a method which suffers from peak overlaps and requires careful calibration and matrix corrections. Analytical problems aside, this could indicate an additional geochemical fractionation process not captured by the shape coefficient model. Such processes are common in low-temperature environments, some examples being the seemingly hydrothermal texture shown by the florencite-(Sm) domains described by Repina et al. (2014). This method does not capture variability caused by the tetrad effect, which may become important at similar low temperatures or unusual fluid chemistries (Irber, 1999; Monecke et al., 2002).

\section{Mineral evolution and nomenclature}

There are fewer minerals with essential REE than expected according to their crustal abundance (Christy, 2015; Hazen et al., 2015a; Higgins and Smith, 2010; Krivovichev et al., 2018; Rieder, 2016). The Ca ionic radius is close to that of $\operatorname{Pr}(112$ pm and $112.6 \mathrm{pm}$, respectively, Shannon, 1976), and consequently the $L R E E$ are often dispersed as trace elements in Ca-rich minerals. Minerals with smaller $\mathrm{Ca}$ sites (such as clinopyroxenes) or with rigid structures will strongly partition HREE relative to
LREE (most notably garnet and zircon, Dubacq and Plunder, 2018) provided that charge balance is achieved. As a result, REE rarely form minerals of their own and instead occur as trace elements in other minerals. Even when REE do form their own minerals, they are dominated mostly by $\mathrm{Ce}$ and $\mathrm{Y}$, with the less abundant REE incorporated as subordinate components in solid solution (i.e. they 'mimic' Ce and Y, Hazen et al., 2015b). No single mineral is capable of isolating a single trivalent REE, but instead incorporate the entire REE series to various degrees. Nonetheless, some minerals have crystal chemical constraints that lead to preferential uptake of a narrower REE range, leading to exceptional concentration of a certain subset relative to the others (Mitchell et al., 1994). Guidelines published by the International Mineralogical Association Commission on New Minerals, Nomenclature and Classification (IMA-CNMNC) require names of minerals containing essential REE to have a suffix denoting the most abundant REE (Hatert et al., 2013; Nickel and Grice, 1998). These suffixes are known as 'Levinson' suffixes (Bayliss and Levinson, 1988; Levinson, 1966). Insofar as nomenclature is inevitably subjective, it could be hard to justify naming a new mineral species. For example, instances of florencite-(Sm) described by Repina et al. (2011) are not individual grains, but rather Sm-dominated thin growth zones inside florencite-(Ce). Hazen (2019) argued that the diversity of REE minerals is an artificial construct by the IMA-CNMNC mineral names rules. He states: “...these split species represent a single natural kind with one stability field that incorporates yttrium and a range of light and heavy REE and thus one paragenetic mode" (Hazen, 2019). However, this statement misses a great deal of nuance in REE geochemistry. Indeed, two minerals with similar REE contents but one containing $\mathrm{La} / \mathrm{Ce}=0.95$ and the other $\mathrm{La} / \mathrm{Ce}=1.05$ will share similar thermodynamic properties and virtually indistinguishable stability fields, even though they will have different mineral names. This is not the case for elements that are farther apart. For example, the thermodynamic properties of bastnäsite-(Ce) and bastnäsite-(Y), or hingganite- $(\mathrm{Ce})$ and hingganite-(Yb) are probably sufficiently different to justify their own mineral species (e.g. Miyawaki and Nakai, 1996) - probably more than zircon and hafnon are justified.

The rarity of REE minerals dominated by Sm, Gd, Dy, Er or Yb is a direct consequence of the composition $(X)$ component of the Hazen and Ausubel (2016) first criterion for mineral rarity: $P-T-$ $X$ range. As shown above, the formation of most $\mathrm{Y}$-absent HREE-dominated species require a negative $\mathrm{Y}$ anomaly, and a negative $\mathrm{Ce}$ anomaly allows greater dominance of $\mathrm{La}$ and $\mathrm{Nd}$. These anomalies require distinct geochemical conditions, either F-rich fluids (Loges et al., 2013) or coexistence of fluorite for Y anomalies (Chebotarev et al., 2019), and oxidising conditions coupled with low temperatures for Ce anomalies (Anenburg et al., 2018; Burnham and Berry, 2014; Sørensen, 1976). The small Sm-dominant zones inside florencite grains reported by Repina et al. (2011) require exceptional formation conditions (Repina et al., 2014). Therefore, 'one paragenetic mode' cannot account for the entire diversity observed in REE mineral name suffixes, and they do not represent 'a single natural kind' (also remembering that the 'natural kind' concept and mineralogy are incompatible; Santana, 2019). The processes that lead to one REE predominating over another are real fractionation processes occurring in Nature. It follows that identification of REE minerals with uncommon dominant elements expand our recognition of attainable extremes in terrestrial geochemical fractionation processes (Hazen and Ausubel, 2016). 


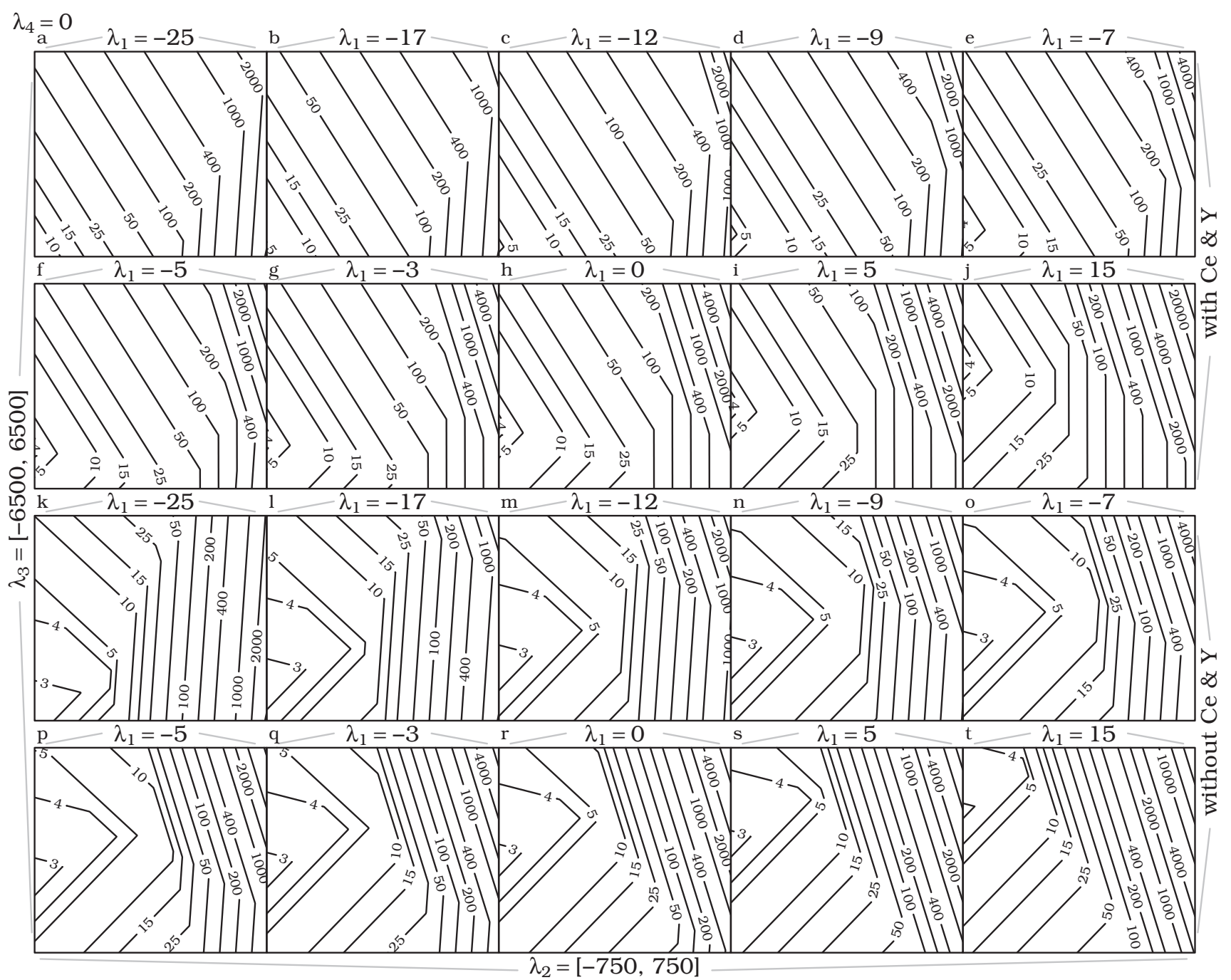

Fig. 6. Contour maps showing the positive Eu anomaly relative to Eu expected from the polynomial required for Eu to be the most abundant REE. Construction of panels is similar to Fig. 3.

The predominant REE in a mineral is not an arbitrary element that gained dominance by happenstance. As seen in Figs 3 and 4, each element dominates a specific region in $\lambda$-space. An arbitrary linear-like path in $n$-dimensional $\lambda_{n}$ space will systematically cross different elements, each with its own characteristic range of REE patterns. Therefore, the Levinson suffix for a mineral is a good indication for its REE pattern type and range of possible $\lambda$ shape coefficients, which may provide information about the process that led to the mineral forming (e.g. by the use of $\psi$ polynomials which represent mineral/melt partition coefficients; O'Neill, 2016).

Notwithstanding the merit of Levinson suffixes in providing information on likely mineral REE patterns and fractionation processes, it has limitations. For example, a '-(La)' suffix does not reveal whether La dominance results from a negative Ce anomaly or from exceptionally high $\lambda_{1}$ and $\lambda_{2}$. Furthermore, the inclusion of $\mathrm{Y}$ in the suffixes obscures much of the variability in the HREE. There is only one Gd mineral and four Yb minerals in which Y contents are low enough to allow a lanthanide to predominate. However, when excluding Y, a much greater diversity is revealed, such as Dy-rich chernovite-(Y) (Ondrejka et al., 2007), Yb-rich
chernovite-(Y) (Alekseev and Marin, 2014) and Gd-rich gagarinite-(Y) (Savelyeva et al., 2019). A more thorough literature review will undoubtedly reveal more Gd-, Dy-, and Yb-dominant species, and potentially Er-dominant species, when disregarding $\mathrm{Y}$. The grouping of lanthanides and $\mathrm{Y}$ together as the REE is reasonable when discussing high-temperature or large-scale processes. Nonetheless, the behaviour of $\mathrm{Y}$ is not identical to the lanthanides (Bédard, 2014; Schoneveld and O'Neill, 2019). For example, in the context of the tetrad effect, the Y/Ho ratio progressively differs from the chondritic in step with the magnitude of the tetrad effect (e.g. Irber, 1999). This difference becomes pronounced on small scales such as those of a mineral grain, leading to strong decoupling of $\mathrm{Y}$ and the lanthanides, and $\mathrm{Y}$ no longer forms a coherent part of the REE (e.g. Anenburg et al., 2020b).

The geochemical behaviour of the REE as part of a series and the resulting dilution of each element by others (Christy, 2015; Mitchell et al., 1994) may not be the only reason for the apparent lack of HREE minerals. The low HREE mineral diversity is probably an artefact of the inclusion of $\mathrm{Y}$ as the Levinson suffix in mineral names. Hazen et al. (2016), for instance, predicts many more REE-carbonates are yet to be found. This study 

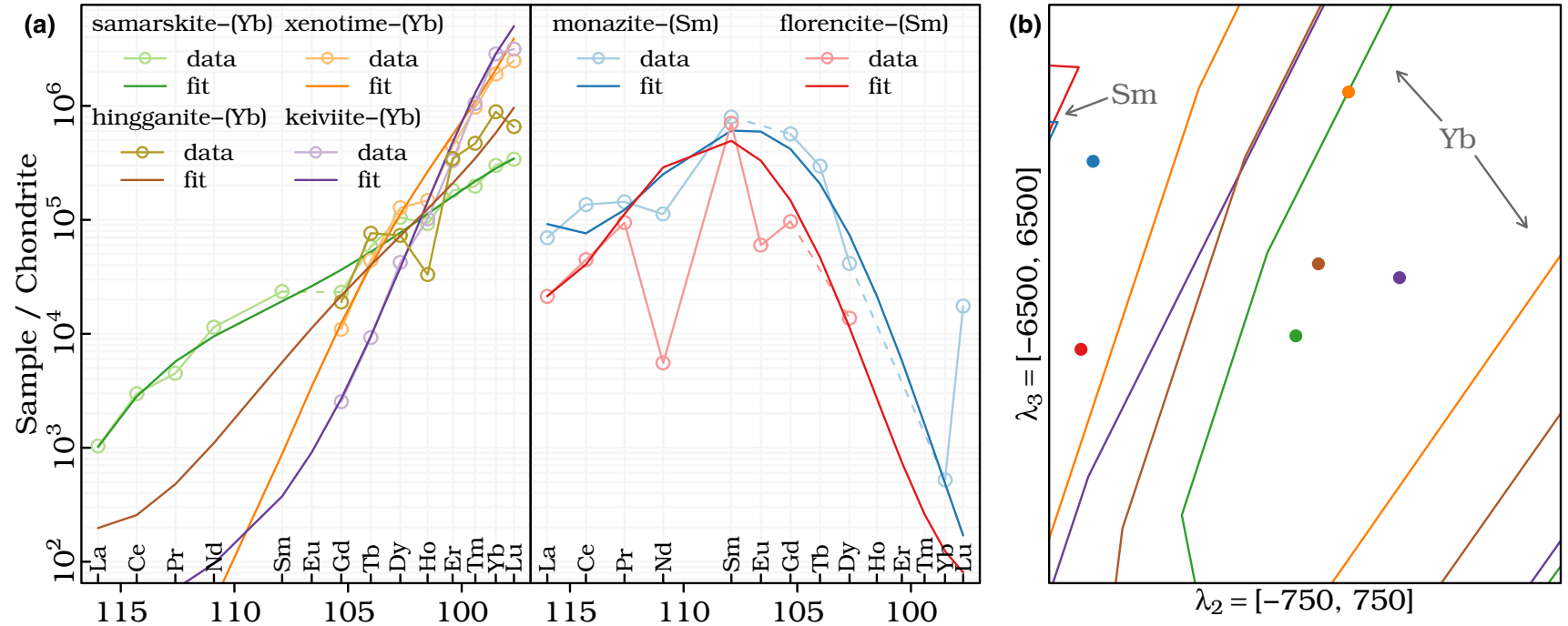

Fig. 7. (a) Literature data for REE minerals and their corresponding polynomial fits. The macro provided by O'Neill (2016) requires data for Ce or La, which was not available for all minerals. See Supplementary material for resulting $\lambda$ values, information on assumed values, and discarded values of poor data quality. (b) Projection of $\lambda$ values used to construct the patterns in $(a)$ to $\lambda_{2}-\lambda_{3}$ space. Coloured lines indicate the field boundaries for dominant Sm (red and blue) and Yb (all others). Data sources: Masau et al. (2002), Repina et al. (2011), Voloshin et al. (1984), Voloshin et al. (1983), Simmons et al. (2006) and Buck et al. (1999).

demonstrates that once HREE mineral chemistry is looked at beyond $\mathrm{Y}$, a greater diversity is discovered. It is possible that many more REE minerals-which reflect real geochemical fractionation processes-will be 'rediscovered' if $\mathrm{Y}$ is removed from Levinson suffixes. Furthermore, future advances in analytical methods are likely to reveal small scale heterogeneities in which unusual REE will predominate (Cook et al., 2017).

Supplementary material. To view supplementary material for this article, please visit https://doi.org/10.1180/mgm.2020.70

Acknowledgements. Hugh O'Neill is thanked for thought-provoking discussions. Stuart Mills is thanked for his editorial handling.

Data. All data and figures in this article were generated using R 4.0.2 from the $R$ script 'REEpatterns. $R$ ' available in the Supplementary materials.

\section{References}

Alekseev V.I. and Marin Y.B. (2014) A tribute to Nicolai Pavlovich Yushkin, one of the discoverers of chernovite. Chernovite-(Y) and other arsenic minerals in rare-metal granites and greisens of the Far East. Geology of Ore Deposits, 55, 601-606. https://doi.org/10.1134/s1075701513070039

Anenburg M., Katzir Y., Rhede D., Jöns N. and Bach W. (2015) Rare earth element evolution and migration in plagiogranites: a record preserved in epidote and allanite of the Troodos ophiolite. Contributions to Mineralogy and Petrology, 169, 25. https://doi.org/10.1007/s00410-0151114-y

Anenburg M., Burnham A.D. and Mavrogenes J.A. (2018) REE redistribution textures in altered fluorapatite: Symplectites, veins and phosphate-silicatecarbonate assemblages from the Nolans Bore P-REE-Th deposit, NT, Australia. The Canadian Mineralogist, 56, 331-354. https://doi.org/10. 3749/canmin. 1700038

Anenburg M., Burnham A.D. and Hamilton J.L. (2020a) Quadrivalent praseodymium in planetary materials. American Mineralogist, 105, https://doi.org/ 10.2138/am-2020-7325

Anenburg M., Mavrogenes J.A. and Bennett V.C. (2020b) The fluorapatite P-REE-Th vein deposit at Nolans Bore: Genesis by carbonatite metasomatism. Journal of Petrology, 61, egaa003 https://oi.org/10.1093/ petrology/egaa003
Balaram V. (2019) Rare earth elements: A review of applications, occurrence, exploration, analysis, recycling, and environmental impact. Geoscience Frontiers, 10, 1285-1303. https://doi.org/10.1016/j.gsf.2018.12.005

Banerjee A. and Chakrabarti R. (2018) Large Ca stable isotopic $\left(\delta^{44 / 40} \mathrm{Ca}\right)$ variation in a hand-specimen sized spheroidally weathered diabase due to selective weathering of clinopyroxene and plagioclase. Chemical Geology, 483, 295-303. https://doi.org/10.1016/j.chemgeo.2018.02.031

Bayliss P. and Levinson A.A. (1988) A system of nomenclature for rare-earth mineral species: Revision and extension. American Mineralogist, 73, 422423.

Bédard J.H. (2006) Trace element partitioning in plagioclase feldspar. Geochimica et Cosmochimica Acta, 70, 3717-3742. https://doi.org/10. 1016/j.gca.2006.05.003

Bédard J.H. (2014) Parameterizations of calcic clinopyroxene - Melt trace element partition coefficients. Geochemistry, Geophysics, Geosystems, 15, 303-336. https://doi.org/10.1002/2013gc005112

Bieseler B., Diehl A., Jöns N., Lucassen F. and Bach W. (2018) Constraints on cooling of the lower ocean crust from epidote veins in the Wadi Gideah section, Oman Ophiolite. Geochemistry, Geophysics, Geosystems, 19, 41954217. https://doi.org/10.1029/2018gc007679

Buck H.M., Cooper M.A., Černý P., Grice J.D. and Hawthorne F.C. (1999) Xenotime- $(\mathrm{Yb}), \mathrm{YbPO}_{4}$, a new mineral species from the Shatford Lake pegmatite group, southeastern Manitoba, Canada. The Canadian Mineralogist, 37, 1303-1306.

Burnham A.D. and Berry A.J. (2014) The effect of oxygen fugacity, melt composition, temperature and pressure on the oxidation state of cerium in silicate melts. Chemical Geology, 366, 52-60. https://doi.org/10.1016/j. chemgeo.2013.12.015

Chakhmouradian A.R. and Zaitsev A.N. (2012) Rare earth mineralization in igneous rocks: sources and processes. Elements, 8, 347-353. https://doi. org/10.2113/gselements.8.5.347

Chebotarev D.A., Veksler I.V., Wohlgemuth-Ueberwasser C., Doroshkevich A.G. and Koch-Müller M. (2019) Experimental study of trace element distribution between calcite, fluorite and carbonatitic melt in the system $\mathrm{CaCO}_{3}+\mathrm{CaF}_{2}+\mathrm{Na}_{2} \mathrm{CO}_{3} \pm \mathrm{Ca}_{3}\left(\mathrm{PO}_{4}\right)_{2}$ at $100 \mathrm{MPa}$. Contributions to Mineralogy and Petrology, 174, 4. https://doi.org/10.1007/s00410-018$1530-\mathrm{x}$

Cheisson T. and Schelter E.J. (2019) Rare earth elements: Mendeleev's bane, modern marvels. Science, 363, 489-493. https://doi.org/10.1126/science. aau7628 
Christy A.G. (2015) Causes of anomalous mineralogical diversity in the Periodic Table. Mineralogical Magazine, 79, 33-49. https://doi.org/10. 1180/minmag.2015.079.1.04

Cook N., Ciobanu C., Ehrig K., Slattery A., Verdugo-Ihl M., Courtney-Davies L. and Gao W. (2017) Advances and opportunities in ore mineralogy. Minerals, 7, 233. https://doi.org/10.3390/min7120233

Coryell C.D., Chase J.W. and Winchester J.W. (1963) A procedure for geochemical interpretation of terrestrial rare-earth abundance patterns. Journal of Geophysical Research, 68, 559-566. https://doi.org/10.1029/ JZ068i002p00559

Davidson J., Turner S. and Plank T. (2013) Dy/Dy*: Variations arising from mantle sources and petrogenetic processes. Journal of Petrology, 54, 525537. https://doi.org/10.1093/petrology/egs076

Deliens M. and Piret P. (1982) Bijvoetite et lepersonnite, carbonates hydratés d'uranyle et de terres rares de Shinkolobwe, Zaïre. The Canadian Mineralogist, 20, 231-238.

Dostal J. (2017) Rare earth element deposits of alkaline igneous rocks. Resources, 6, 34. https://doi.org/10.3390/resources6030034

Dubacq B. and Plunder A. (2018) Controls on trace element distribution in oxides and silicates. Journal of Petrology, 59, 233-256. https://doi.org/10. 1093/petrology/egy027

Ferru G., Reinhart B., Bera M.K., Olvera de la Cruz M., Qiao B. and Ellis R.J. (2016) The lanthanide contraction beyond coordination chemistry. Chemistry - A European Journal, 22, 6899-8904. https://doi.org/10.1002/ chem.201601032

Frei D., Liebscher A., Franz G. and Dulski P. (2004) Trace element geochemistry of epidote minerals. Pp. 553-606 in: Epidotes. (A. Liebscher and G. Franz, editors). Reviews in Mineralogy and Geochemistry, 56. Mineralogical Society of America and the Geochemical Society, Washington, DC, https://doi.org/10.2138/gsrmg.56.1.553

Harkins W.D. (1917) The evolution of the elements and the stability of complex atoms. I. A new periodic system which shows a relation between the abundance of the elements and the structure of the nuclei of atoms. Journal of the American Chemical Society, 39, 856-879. https://doi.org/10. 1021/ja02250a002

Hatert F., Mills S.J., Pasero M. and Williams P.A. (2013) CNMNC guidelines for the use of suffixes and prefixes in mineral nomenclature and for the preservation of historical names. European Journal of Mineralogy, 25, 113-115. https://doi.org/10.1127/0935-1221/2013/0025-2267

Hazen R.M. (2014) Data-driven abductive discovery in mineralogy. American Mineralogist, 99, 2165-2170. https://doi.org/10.2138/am-2014-4895

Hazen R.M. (2019) An evolutionary system of mineralogy: Proposal for a classification of planetary materials based on natural kind clustering. American Mineralogist, 104, 810-816. https://doi.org/10.2138/am-2019-6709CCBYNCND

Hazen R.M. and Ausubel J.H. (2016) On the nature and significance of rarity in mineralogy. American Mineralogist, 101, 1245-1251. https://doi.org/10. 2138/am-2016-5601CCBY

Hazen R.M., Grew E.S., Downs R.T., Golden J. and Hystad G. (2015a) Mineral ecology: chance and necessity in the mineral diversity of terrestrial planets. The Canadian Mineralogist, 53, 295-324. https://doi.org/10.3749/canmin. 1400086

Hazen R.M., Hystad G., Downs R.T., Golden J.J., Pires A.J. and Grew E.S. (2015b) Earth's "missing" minerals. American Mineralogist, 100, 23442347. https://doi.org/10.2138/am-2015-5417

Hazen R.M., Hummer D.R., Hystad G., Downs R.T. and Golden J.J. (2016) Carbon mineral ecology: Predicting the undiscovered minerals of carbon. American Mineralogist, 101, 889-906. https://doi.org/10.2138/am-20165546

Higgins M.D. and Smith D.G.W. (2010) A census of mineral species in 2010. Elements, 6, 346.

Irber W. (1999) The lanthanide tetrad effect and its correlation with K/Rb, Eu/ $\mathrm{Eu} *, \mathrm{Sr} / \mathrm{Eu}, \mathrm{Y} / \mathrm{Ho}$ and $\mathrm{Zr} / \mathrm{Hf}$ of evolving peraluminous granite suites. Geochimica et Cosmochimica Acta, 63, 489-508. https://doi.org/10.1016/ s0016-7037(99)00027-7

Krivovichev V.G. and Charykova M.V. (2017) Mineral systems, their types and distribution in nature. I. Khibiny, Lovozero and the Mont SaintHilaire. Geology of Ore Deposits, 58, 551-558. https://doi.org/10.1134/ s1075701516070059
Krivovichev V.G., Charykova M.V. and Krivovichev S.V. (2018) The concept of mineral systems and its application to the study of mineral diversity and evolution. European Journal of Mineralogy, 30, 219-230. https://doi.org/ 10.1127/ejm/2018/0030-2699

Kuroda P.K. (1982) Elements 43 and 61 in nature. Pp. 15-29 in: The Origin of the Chemical Elements and the Oklo Phenomenon. Springer, Berlin. https:// doi.org/10.1007/978-3-642-68667-2_3

Levinson A.A. (1966) A system of nomenclature for rare-earth minerals. American Mineralogist, 51, 152-158.

Loges A., Migdisov A.A., Wagner T., Williams-Jones A.E. and Markl G. (2013) An experimental study of the aqueous solubility and speciation of $\mathrm{Y}(\mathrm{III})$ fluoride at temperatures up to $250{ }^{\circ} \mathrm{C}$. Geochimica et Cosmochimica Acta, 123, 403-415. https://doi.org/10.1016/j.gca.2013.07.031

Masau M., Černý P., Cooper M.A., Chapman R. and Grice J.D. (2002) Monazite-(Sm), a new member of the monazite group from the Annie Claim \#3 granitic pegmatite, Southeastern Manitoba. The Canadian Mineralogist, 40, 1649-1655. https://doi.org/10.2113/gscanmin. 40.6.1649

McLeod C. and Shaulis B. (2018) Rare earth elements in planetary crusts: Insights from chemically evolved igneous suites on Earth and the Moon. Minerals, 8, 455. https://doi.org/10.3390/min8100455

Minami M. and Masuda A. (1997) Approximate estimation of the degree of lanthanide tetrad effect from the data potentially involving all lanthanides. Geochemical Journal, 31, 125-133.

Mitchell R.H., Novgorodova M.I. and Semenov E.I. (1994) Chemical composition of minerals, crystallochemical constraints and the nature of impurities. Pp. 2-12 in: Advanced Mineralogy, Volume 1: Composition, Structure, and Properties of Mineral Matter: Concepts, Results and Problems (A.S. Marfunin, editor). Springer, Berlin. https://doi.org/10.1007/978-3-64278523-8_1

Miyawaki R. and Nakai I. (1996) Crystal chemical aspects of rare earth minerals. Pp. 21-40 in: Rare Earth Minerals, Chemistry, Origin and Ore Deposits (A.P. Jones, F. Wall and C.T. Williams, editors). Chapman and Hall, London.

Monecke T., Kempe U., Monecke J., Sala M. and Wolf D. (2002) Tetrad effect in rare earth element distribution patterns: a method of quantification with application to rock and mineral samples from granite-related rare metal deposits. Geochimica et Cosmochimica Acta, 66, 1185-1196. https://doi. org/10.1016/s0016-7037(01)00849-3

Nickel E.H. and Grice J.D. (1998) The IMA Commission on New Minerals and Mineral Names: procedures and guidelines on mineral nomenclature, 1998. The Canadian Mineralogist, 36, 913-926.

Ondrejka M., Uher P., Pršek J. and Ozdín D. (2007) Arsenian monazite-(Ce) and xenotime-(Y), REE arsenates and carbonates from the Tisovec-Rejkovo rhyolite, Western Carpathians, Slovakia: Composition and substitutions in the (REE, $\mathrm{Y}) \mathrm{XO}_{4}$ system ( $\left.\mathrm{X}=\mathrm{P}, \mathrm{As}, \mathrm{Si}, \mathrm{Nb}, \mathrm{S}\right)$. Lithos, 95, 116-129. https://doi.org/10.1016/j.lithos.2006.07.019

O'Neill H.S.C. (2016) The smoothness and shapes of chondrite-normalized rare earth element patterns in basalts. Journal of Petrology, 57, $1463-$ 1508. https://doi.org/10.1093/petrology/egw047

Pack A., Russell S.S., Shelley J.M.G. and van Zuilen M. (2007) Geo- and cosmochemistry of the twin elements yttrium and holmium. Geochimica et Cosmochimica Acta, 71, 4592-4608. https://doi.org/10.1016/j.gca.2007.07.010

Palme H., Lodders K. and Jones A. (2014) Solar system abundances of the elements. Pp. 15-36 in: Treatise on Geochemistry (Second Edition), Volume 2: Planets, Asteroids, Comets and The Solar System (A.M. Davis, editor). Elsevier, Amsterdam. https://doi.org/10.1016/b978-0-08-095975-7. 00118-2

Raymond K.N., Wellman D.L., Sgarlata C. and Hill A.P. (2010) Curvature of the lanthanide contraction: An explanation. Comptes Rendus Chimie, 13, 849-852. https://doi.org/10.1016/j.crci.2010.03.034

Repina S.A., Popova V.I., Churin E.I., Belogub E.V. and Khiller V.V. (2011) Florencite- $(\mathrm{Sm})-(\mathrm{Sm}, \mathrm{Nd}) \mathrm{Al}_{3}\left(\mathrm{PO}_{4}\right)_{2}(\mathrm{OH})_{6}$ : A new mineral species of the alunite-jarosite group from the subpolar urals. Geology of Ore Deposits, 53, 564-574. https://doi.org/10.1134/s1075701511070191

Repina S.A., Khiller V.V. and Makagonov E.P. (2014) Microheterogeneity of crystal growth zones as a result of REE fractionation. Geochemistry International, 52, 1057-1071. https://doi.org/10.1134/s0016702914100085 
Rieder M. (2016) The mineralogical system: Can global plots teach us something new? Mineralogical Magazine, 80, 239-248. https://doi.org/10.1180/ minmag.2016.080.012

Rudnick R.L. (1992) Restites, Eu anomalies and the lower continental crust. Geochimica et Cosmochimica Acta, 56, 963-970. https://doi.org/10.1016/ 0016-7037(92)90040-p

Rudnick R.L. and Gao S. (2014) Composition of the continental crust. Pp. 151 in: Treatise on Geochemistry (Second Edition), Volume 4: The Crust (R.L. Rudnick, editor). Elsevier, Amsterdam. https://doi.org/10.1016/b9780-08-095975-7.00301-6

Santana C. (2019) Mineral misbehavior: why mineralogists don't deal in natural kinds. Foundations of Chemistry, 21, 333-343. https://doi.org/10.1007/ s10698-019-09338-3

Savelyeva V.B., Bazarova E.P., Khromova E.A. and Kanakin S.V. (2019) REE minerals in the rocks of the Katugin rare metal deposit, East Transbaikalia: Behavior of lanthanides and Y during crystallization of an F-saturated agpaitic melt. Geology of Ore Deposits, 60, 643-657. https:// doi.org/10.1134/s1075701518080093

Schoneveld L. and O'Neill H.S.C. (2019) The influence of melt composition on the partitioning of trace elements between anorthite and silicate melt. Contributions to Mineralogy and Petrology, 174, 13. https://doi.org/10. 1007/s00410-019-1548-8

Seitz M., Oliver A.G. and Raymond K.N. (2007) The lanthanide contraction revisited. Journal of the American Chemical Society, 129, 11153-11160. https://doi.org/10.1021/ja072750f

Shannon R.D. (1976) Revised effective ionic radii and systematic studies of interatomic distances in halides and chalcogenides. Acta Crystallographica A32, 751-767. https://doi.org/10.1107/s0567739476001551

Simmons W.B., Hanson S.L. and Falster A.U. (2006) Samarskite-(Yb): A new species of the samarskite group from the Little Patsy pegmatite, Jefferson County, Colorado. The Canadian Mineralogist, 44, 1119-1125. https://doi. org/10.2113/gscanmin.44.5.1119

Sørensen O.T. (1976) Thermodynamic studies of the phase relationships of nonstoichiometric cerium oxides at higher temperatures. Journal of Solid State Chemistry, 18, 217-233. https://doi.org/10.1016/0022-4596(76) 90099-2

Taylor S.R. (1962) Meteoritic and terrestrial rare earth abundance patterns. Geochimica et Cosmochimica Acta, 26, 81-88. https://doi.org/10.1016/ 0016-7037(62)90007-8

Verplanck P.L., Mariano A.N. and Mariano Jr. A. (2016) Rare earth element ore geology of carbonatites. Pp. 5-32 in: Rare Earth and Critical Elements in Ore Deposits (P.L. Verplanck and M.W. Hitzman, editors). Society of Economic Geologists, Littleton, Colorado, USA. https://oi.org/10.5382/ Rev.18.01

Voloshin A.V., Pakhomovsky Y.A. and Tyusheva F.N. (1983) Keiviite $\mathrm{Yb}_{2} \mathrm{Si}_{2} \mathrm{O}_{7}$, a new ytterbium silicate from amazonitic pegmatites of the Kola Peninsula. Mineralog Zhurnal, 5, 94-99.

Voloshin A.V., Pakhomovskii Y.A., Men'shikov Y.P., Povarennykh A.S., Matvinenko E.N. and Yakubovich O.V. (1984) Hingganite-(Yb), a new mineral from Amazonite pegmatite of the Kola Peninsula. International Geology Review, 26, 60-63. https://doi.org/10.1080/00206818409452995

Williams M.J., Schoneveld L., Mao Y., Klump J., Gosses J., Dalton H., Bath A. and Barnes S. (2020) Pyrolite: Python for geochemistry. Journal of Open Source Software, 5, 2314. https://doi.org/10.21105/joss.02314

\section{Appendix}

$A L a m b d a R$ is an online interactive app developed in $R$ that generates REE patterns from input describing the REE pattern shape, available at https://lambdar.rses.anu.edu.au/alambdar/. The app takes numerical input of $\lambda_{0}$ to $\lambda_{4}$, $\mathrm{Eu}$ and $\mathrm{Ce}$ anomalies and $\mathrm{Y} / \mathrm{Ho}$ ratio. It generates REE abundances from which it shows a normalised REE pattern according to a normalisation scheme selected by the user. A pie chart showing the relative properties of all REE is also given. It is possible to export the plots in either pdf (vector) or png (raster) formats, and export the data in comma separated values (csv) format. The app also allows upload of files in csv format containing multiple combinations of $\lambda_{0}$ to $\lambda_{4}$, and it generates a downloadable file containing the resulting REE abundances in $\mu \mathrm{g} \mathrm{g}^{-1}$ units. Future versions will include tetrad effects for a more comprehensive REE pattern generation functionality (e.g. Irber, 1999; Minami and Masuda, 1997; Monecke et al., 2002).

For calculating a REE pattern using $\lambda$ shape coefficients, the app uses a matrix $\boldsymbol{F}$ that includes all $\mathrm{f}_{n}$ values:

$$
\boldsymbol{F}=\left(\begin{array}{ccc}
\mathrm{f}_{\mathrm{La}, 1} & \cdots & \mathrm{f}_{\mathrm{La}, 4} \\
\mathrm{f}_{\mathrm{Ce}, 1} & \cdots & \mathrm{f}_{\mathrm{Ce}, 4} \\
\vdots & \ddots & \vdots \\
\mathrm{f}_{\mathrm{Lu}, 1} & \cdots & \mathrm{f}_{\mathrm{Lu}, 4}
\end{array}\right)=\left(\begin{array}{ccc}
0.1052 & \cdots & 8.29 \times 10^{-6} \\
0.0882 & \cdots & -7.16 \times 10^{-6} \\
\vdots & \ddots & \vdots \\
-0.0778 & \cdots & 9.41 \times 10^{-6}
\end{array}\right)
$$

The full set of values is available in O'Neill (2016) or in the Supplementary code. Each REE pattern can be described as a combination of $\lambda$ values, and a column vector is defined:

$$
\vec{\lambda}=\left(\begin{array}{c}
\lambda_{1} \\
\lambda_{2} \\
\lambda_{3} \\
\lambda_{4}
\end{array}\right)
$$

The REE contents for each corresponding $\vec{\lambda}$ can be calculated using matrix multiplication:

$$
\overrightarrow{\ln \left(\frac{[\mathrm{REE}]}{[\mathrm{REE}]_{\mathrm{Cl}}}\right)}=\vec{F} \vec{\lambda}+\lambda_{0}
$$

The choice of the logarithm base does not change the pattern shape. However, in some cases it might be desirable to transform the values to base 10 which is achieved via:

$$
\overrightarrow{\log \left(\frac{[\mathrm{REE}]}{[\mathrm{REE}]_{\mathrm{Cl}}}\right)}=\log e \times \overrightarrow{\ln \left(\frac{[\mathrm{REE}]}{[\mathrm{REE}]_{\mathrm{CI}}}\right)}
$$

If required, concentration values in $\mu \mathrm{g} \mathrm{g}^{-1}$ are calculated using:

$$
\overrightarrow{[\mathrm{REE}]}=\vec{C} \cdot e^{\overrightarrow{\ln \left(\frac{[\mathrm{REE}]}{[\mathrm{REE}]_{\mathrm{CI}}}\right)}}=\vec{C} \cdot 10^{\overline{\log \left(\frac{[\mathrm{REE}]}{[\mathrm{REE}]_{\mathrm{CI}}}\right)}}
$$

Where $\vec{C}$ is a vector of CI values from O’Neill (2016). 